Nefise ÇETIN1

Sibel MANSUROĞLU2

${ }^{1}$ Konyaaltı Belediyesi, Park ve Bahçeler Müdürlüğü, 07070, Antalya / Türkiye

2 Akdeniz Üniversitesi, Ziraat Fakültesi, Peyzaj Mimarlığı Bölümü, 07070, Antalya /Türkiye sorumlu yazar: nefisecetinn@gmail.com

Anahtar Sözcükler:

Kurakçıl peyzaj, bitkisel tasarım, su tasarrufu

Key Words:

Xeriscape, planting design, water saving

\section{Akdeniz Koşullarında Kurakçıl Peyzaj Düzenlemelerinde Kullanılabilecek Bitki Türlerinin Belirlenmesi: Antalya/Konyaaltı Örneği}

\author{
Determination of Plant Species can be used in Xeriscape \\ design under Mediterranean conditions : The Sample of \\ Antalya/Konyaaltı
}

Alıış (Received): 20.03.2017～Kabul tarihi (Accepted): 12.06.2017

\section{ÖZET}

Deyzaj tasarımlarında yanlış bitki seçimleri, geniş alanlarda çim ve mevsimlik bitki kullanımları sınırlı su kaynakları üzerindeki baskıyı arttırabilmektedir. Özellikle Akdeniz iklim koşullarında, peyzaj tasarımında yanlış bitki seçimi nedeniyle yaz aylarında bitkiler kurumakta, hatta ölmektedir. Bu nedenle yoğun sulama gerektiren klasik peyzaj anlayışından vazgeçilerek, az su kullanılan 'Kurakçıl Peyzaj'(Xeriscape) gibi peyzaj yaklaşımlarına gereksinim duyulmaktadır. Bu çalışmada, bitkisel tasarımda su tasarrufu sağlamada en önemli konunun doğru bitki seçimi olduğu ve alanın doğal yapı özelliklerine uygun bitkilerle yapılan tasarımlarla peyzajların sürdürülebilirliğinin artırılabileceği yaklaşımı ile hareket edilmiştir. Kurak dönemin uzun sürdüğü Akdeniz koşullarında kurakçıl peyzaj düzenlemelerinde kullanılabilecek bitki türlerinin ve özelliklerinin belirlenmesi amaçlanmış, uygulamalarda yarar sağlaması için bitkilerin fidanlıklarda bulunabilirlikleri araştırılmıştır. Ayrıntılı iklim analizlerinin de yapıldığı çalışma Antalya/Konyaaltı ilçesi örneğinde yürütülmüştür. Kuraklığa dayanıklı bitki kullanımının yaygınlaştırııması ve fidanlıkta bulunmayan kuraklığa toleranslı türlerin üretimine geçilmesi konularında öneriler geliştirilmiştir.

\section{ABSTRACT}

$F^{2}$

ailure in plant selection, using turf and annual plants over large areas in andscape designs increase the pressure on already limited water resources. Especially in mediterranean climate conditions, because of the incorrect plant choices in landscape design plants dry even die during the summer months. Accordingly, such as "Xeriscaping" which uses limited water, must be adopted instead of traditional landscape designs that require a large amount of irrigation. This study is conduct on the approach that the most important subject about water saving in planting design is correct selection of plants and, that the sustainability of landscape can be improved by designing with plants suitable for the natural structural features of the area. The study aims to determine the plant species and the features of these plants that can be used for xeriscape design under mediterranean conditions which has long arid periods, for the benefit of landscape applications the availability of these plants in nurseries was inquired. Climate was analysed elaborately by studying the sample of Antalya/Konyaaltı county. Some suggestions have been developed to popularize the use of drought tolerant plants and on the production of drought tolerant plants not found in the nursery. 


\section{GíRiş}

Kaynakların savurganca, hiç tükenmeyecekmiş gibi kullanılması ve yoğun baskılar nedeniyle doğa kendini yenileyemez hale gelmiştir. Kaynakların yanlış kullanılarak tüketilmesi ve çevre kirliliği sorunlarının evrenselliğinin anlaşılmasıyla doğanın tamirinin ve yerine konulmasının bir sürece bağlı olduğu fark edilmiş, bugünün sorunlarının gelecek nesillerde de etkin olacağı anlaşılmıştır. Böylelikle vakit kaybetmeden çözüm aranması gerektiği ve bu çözümlerin derhal hayata geçirilmesi gerekliliği ortaya çıkmıştır (Atıl ve ark. 2005).

$\mathrm{Bu}$ kaynaklardan belki de en önemlisi olan su kaynaklarının verimli kullanımı için çeşitli çalışmalar yapılmaktadır. Peyzaj mimarlığında ise mevcut su kaynaklarının etkin ve geri dönüştürülebilir kullanımını benimseyen su-etkin peyzaj yaklaşımı olan Kurakçıl Peyzaj (Xeriscape) kavramı üzerine çalışmalar yapılmaya başlanmıştır. Kurakçıl peyzajda 7 ilke benimsenmiştir, bunlardan uygun bitki türlerinin seçimi ve kuraklığa dayanıklı çim alanların oluşturulmasının en önemli ilkeler olduğu düşünülmektedir. Yeşil alanların sürdürülebilirliğini sağlamak için bitki seçimi yaparken bölgenin başta iklim koşulları olmak üzere doğal yapı özelliklerinin, bitkiler üzerine etkilerinin dikkate alınması gerekmektedir. Ülkemizde Taner (2010), Çakıroğlu (2011), Baykan ve Birişçi (2013), yurt dışında Keane (1995), Wade ve ark. (2007) gibi araştırıcılar kuraklığa dayanıkı bitkilere yönelik tablolar oluşturmuşlardır. Su tasarrufu sağlama düşüncesiyle, Akdeniz koşullarında kurakçıl peyzaj düzenlemelerinde kullanılabilecek bitki türlerinin ve bitkisel tasarıma yönelik özelliklerinin belirlenmesinin amaçlandığı bu çalışmada, Antalya Konyaaltı ilçesinin doğal yapı özellikleri incelenmiş, kurakçıl peyzajla ilgili veri toplanmış, ayrıntılı bir literatür taraması yapılıp, çeşitli faktörler dahilinde bitki listesi hazırlanmış, değerlendirilmiş ve bazı öneriler geliştirilmiştir.

\section{MATERYAL ve YÖNTEM \\ Materyal}

Çalışmanın ana materyalini, Akdeniz bölgesini temsilen seçilen Antalya Büyükşehir Belediyesi'ne bağlı bulunan Konyaaltı ilçesi oluşturmaktadır. 562.4 km²'lik yüz ölçümü olan Konyaaltı, 2014 yılına göre 145.648 kişilik bir nüfusa sahiptir (Konyaaltı Kaymakamlığı, 2015 ve TÜiK, 2015). Alanın doğal yapı özellikleri belirlenirken toprak ve morfoloji için Köy Hizmetleri Genel Müdürlüğü'nün (KHGM, 1993a) hazırlamış olduğu toprak haritası ve Antalya illi Arazi Varlığı adlı rapordan (KHGM,1993b) hidroloji için de aynı rapordan yararlanılarak, jeoloji için Maden Tetkik ve Arama Genel Müdürlüğü'nün (MTA, 1997)
$1 \backslash 100.000$ ölçekli jeoloji haritası ve iklim özellikleri için Meteoroloji Genel Müdürlüğü (MGM, 2015) Antalya Meteoroloji 4. Bölge Müdürlüğü 36 enlem 30 boylam ile denizden 51 metre yükseklikte bulunan 17300 numaralı "Antalya Havaalanı" meteoroloji iklim istasyonundan 1960-2014 yıllarına ait uzun yıllar ortalaması verileri kullanılarak ortaya konulmuştur. Ilç̧e sınırları belirlenirken, Konyaaltı Belediyesi'nden (2014) temin edilen haritadan yararlanılmıştır. Bitki listesi oluşturulurken, hangi bitkilerin Akdeniz koşullarında uygun olabileceği, orijini, tipi, yaprak dökme durumu, peyzaj için çekiciliği, Akdeniz bölgesinin doğal bitki örtüsündeki varlığı konularında; Akalın (1952), Orçun (1972), Orçun (1975), Yaltırık (1984), Ferguson (1986), Ulubelen ve ark. (1986), Odabaş (1989), Baktır (1994), Göktürk (1994), Keane (1995), Horowitz (1996), Yılmaz (1996), Ceylan (1999), Oral (1999), University of California Cooperative Extension California Department of Water Resources (2000), Welsh (2000), Gildemeister (2002), Bridwell (2003), Burnie ve ark. (2004), Ebcioğlu (2004), Randhawa ve Mukhopadhyay (2004), Altan (2005), Wade ve ark. (2007), Filippi (2008), Karahan ve Angın (2008), Redbud Chapter Western Nevada ve Placer Counties (2008), Kaya ve Aladağ (2009), Önder ve Polat (2009), Schellman (2009), Avcıoğlu ve Geren (2012), Gül ve ark. (2012), Kumar ve Singh (2012), Mamıkoğlu (2012), Baykan ve Biriş̧̧i (2013), Stephens (2015) tarafından yapılan çalışmalar irdelenmiştir. Bitkilerin fidanlıkta bulunabilirliği konusunda bilgi sağlanan firma ve kurumlar ise Seki Peyzaj, Atölye Peyzaj, Mavi Peyzaj, Ekovizyon Peyzaj, Eko Garden, Imaj Peyzaj, Tetikler Peyzaj, Kurgu Peyzaj, Pey Art Peyzaj, Damla Peyzaj, İnci Peyzaj, Zirve Peyzaj, Fito Tohumculuk, Çimsan, Antalya Rulo Çim, Maro Tarım, Antalya Orman Fidanlığı, Konyaaltı Belediyesi ve Antalya Büyükşehir Belediyesi Fidanlığı'dır.

\section{Yöntem}

Araştırma dört aşamada yürütülmüştür. İlk olarak alanın doğal yapı özellikleri (jeoloji, morfoloji, toprak, hidroloji, iklim) ortaya konulmuştur. İkinci aşamada iklim istasyonundan alınan yıllık ortalama sıcaklık $\left({ }^{\circ} \mathrm{C}\right)$ ve ortalama yağış $(\mathrm{mm})$ değerleri kullanılarak Walter (1970)'a göre çizilen hidrometrik diyagram ile araştırma alanının kurak dönemi bulunmuş (Çepel, 1995), alanın iklim tipinin bulunması amacıyla Erinç'in (1965) "Yağış Etkenliği İndisi" formülü kullanılmıştır. Üçüncü aşamada kurakçıl peyzajla ilgili veri toplanmıştır. Dördüncü aşamada ayrıntılı bir literatür taraması yapılarak, Akdeniz koşullarında bitkisel tasarım çalışmalarında kullanılabilecek kuraklığa dayanıklı bitkiler ve özelliklerini içeren liste hazırlanmış, değerlendirmesi yapılmış ve bazı öneriler geliştirilmiştir. 


\section{ARAŞTIRMA BULGULARI ve TARTIŞMA Doğal Yapı Özellikleri}

Peyzaj çalışmalarında alana ait doğal yapı özelliklerinin bilinmesi, bitkisel ve yapısal düzenlemelerin bu verilere göre yapılması, sürdürülebilir sonuçlara ulaşmak için gereklidir. Bu nedenle çalışma alanının bazı doğal yapı özellikleri haritalanmış ve analiz sonuçları aşağıda özetlenmiştir.

Konyaaltı ilçesinin jeolojik yapısı incelendiğinde çeşitli oluşumlarının olduğu görülmektedir. Alanda $\% 26.76$ ile en fazla yer kaplayan jeolojik oluşum kireçtaşı olup, $\% 46.59$ ile sarp (\%30 ve üzeri eğime sahip), \%21.02 ile düz-düze yakın (\% $0-2$ ) araziler hakimdir. Kıyıya yakın bölümler düze yakın arazilerden oluşurken, kıyıdan uzaklaştıkça eğimli alanlar artmaktadır. Buna bağlı olarak herhangi bir yöneyin hakim olmadığı araziler \%17.44 oranında en fazla alanı kaplamaktadır. Kırmızı Akdeniz Toprakları (\%83.13), çok sığ topraklar $(0-20 \mathrm{~cm})$ (\%52.37), VII. sınıf topraklar (\%48.82) ile toprak yetersizliği, eğim ve erozyon zararı olan alanların fazlalığı (\%40.84 oranında) dikkat çekmektedir. İlçe sınırları içerisinde bulunan başlıca akarsu kaynakları Boğaçayı, Arapsuyu, Sarısu Çayları'dır. Boğaçayı; Karaman, Doyran ve Çandır isimli üç çaydan oluşan, yaklaşık 48 km uzunluğunda olan Boğaçayı'nın suyu tuzluluk bakımından ikinci, alkalilik bakımından birinci sınıf sulama suyu niteliğindedir (KHGM, 1993b).

Alan iklimsel açıdan incelendiğinde, elde edilen iklim verileri ve rasat süreleri Çizelge 1'de sunulmuştur. $\mathrm{Bu}$ verilere göre ortalama sıcaklık $18.4^{\circ} \mathrm{C}$, ortalama yüksek sıcaklık $24.1^{\circ} \mathrm{C}$, ortalama düşük sıcaklık $13.5^{\circ} \mathrm{C}^{\prime}$ dir. En yüksek sıcaklık 12.07.2000 tarihinde $45^{\circ} \mathrm{C}$, en düşük sıcaklık 15.02.2004 tarihinde $-4^{\circ} \mathrm{C}$ olarak ölçülmüştür. En sıcak aylar; Temmuz, Ağustos, Eylül, en soğuk aylar; Aralık, Ocak, Şubat'tır.

Çizelge 1. Antalya Havaalanı İstasyonu'ndan alınan iklim verileri ve rasat süreleri (MGM 2015)

Table 1. Climate data and observation times from Antalya Airport Station (MGM 2015)

\begin{tabular}{|c|c|c|}
\hline \multirow{2}{*}{$\begin{array}{l}\text { İstasyon Adı } \\
\text { İklim Elemanları }\end{array}$} & \multicolumn{2}{|c|}{ Antalya Havaalanı } \\
\hline & Rasat Süresi (Yıl) & Değerler \\
\hline En Yüksek Sıcaklık ( ${ }^{\circ} \mathrm{C} /$ Tarih) & 47 & $45 / 12.07 .2000$ \\
\hline Ortalama Yüksek Sıcaklık $\left({ }^{\circ} \mathrm{C}\right)$ & 47 & 24.1 \\
\hline En Düşük Sıcaklık ( ${ }^{\circ} \mathrm{C} /$ Tarih) & 47 & $-4.0 / 15.02 .2004$ \\
\hline Ortalama Düşük Sıcaklık $\left({ }^{\circ} \mathrm{C}\right)$ & 47 & 13.5 \\
\hline Ortalama Sıcaklık $\left({ }^{\circ} \mathrm{C}\right)$ & 47 & 18.4 \\
\hline Min. Sıcaklık $20^{\circ} \mathrm{C}$ ve üzeri olduğu gün sayısı & 47 & 79.7 \\
\hline Min. Sıcaklık $15^{\circ} \mathrm{C}$ ve üzeri olduğu gün sayısı & 47 & 156 \\
\hline Min. Sıcaklık $10^{\circ} \mathrm{C}$ ve üzeri olduğu gün sayısı & 47 & 238.3 \\
\hline Ortalama Bağıl Nem (\%) & 47 & 63.2 \\
\hline En Düşük Bağıl Nem (\%) & 47 & 2 \\
\hline Ortalama Açık Gün Sayısı (Adet) & 47 & 148 \\
\hline Ortalama Bulutlu Gün Sayısı (Adet) & 47 & 177 \\
\hline Ortalama Kapalı Gün Sayısı (Adet) & 47 & 40.2 \\
\hline Ortalama Toplam Yağış Miktarı (mm) & 51 & 1005.1 \\
\hline Günlük En Çok Yağış Miktarı (mm) & 51 & 331.5 \\
\hline Ortalama Dolulu Gün Sayısı (Adet) & 51 & 2.2 \\
\hline Ortalama Kırağılı Gün Sayısı (Adet) & 51 & 1.1 \\
\hline Ortalama Rüzgar Hızı (m/sn) & 47 & 3 \\
\hline En Hızlı Rüzgar Hızı ve Yönü (m/snyön) & 47 & $43.2^{\mathrm{GGD}}$ \\
\hline Ortalama Fırtınalı Gün Sayısı (Adet) & 47 & 18.3 \\
\hline Ortalama Kuvvetli Rüzgarlı Gün Sayısı (Adet) & 47 & 64.9 \\
\hline Ortalama Buharlaşma (mm) & 49 & 1826.5 \\
\hline Günlük En Çok Buharlaşma (mm) & 49 & 23.6 \\
\hline Günlük Ortalama Güneşlenme Süresi (sa-da) & 51 & 8,3 \\
\hline Günlük Ortalama Güneşlenme Şiddeti $\left(\mathrm{cal} / \mathrm{cm}^{2}\right)$ & 36 & 390,2 \\
\hline
\end{tabular}

\section{İklim Analizleri}

İklim istasyonundan alınan değerlere göre oluşturulan hidrometrik diyagram incelendiğinde Nisan sonundan Eylül sonuna kadar yaklaşık 5 ay süren kurak bir dönem yaşandığı görülmektedir (Şekil 1). Mevsimlere ve yıllık ortalama değerlere göre hesaplanan sonuçları incelendiğinde, alanının iklim tipinin, ilkbahar ve sonbaharda yarı kurak, yazın kurak, kışın yarı nemlinemli iklim tipine sahip iken, yıllık değerlere göre yarı nemli-nemli iklim tipine girdiği ortaya çıkmıştır (Çizelge 2). Bu farklılık yağış ve sıcaklık değerlerinin mevsimlere dağııımından kaynaklanmaktadır. 


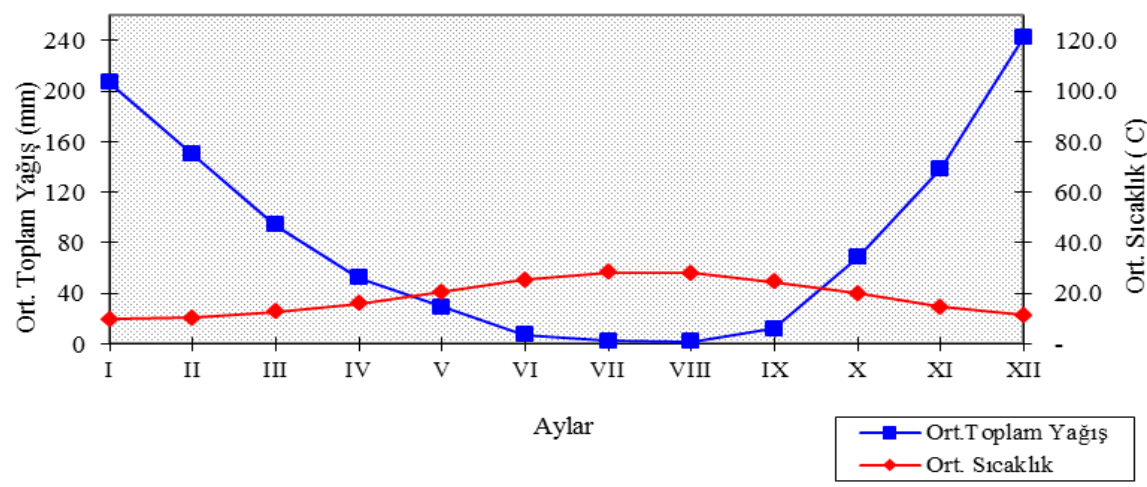

Şekil 1. Antalya Havaalanı İstasyonu hidrometrik diyagramı

Figure 1. Hydrometric diagram of Antalya Airport Station

Çizelge 2. Antalya Havaalanı İstasyonu verilerine göre mevsimsel ve yıllık yağış etkenliği değerleri ile iklim tipleri Table 2. According to the data of Antalya Airport Station, seasonal and annual rainfall activity values and climate types

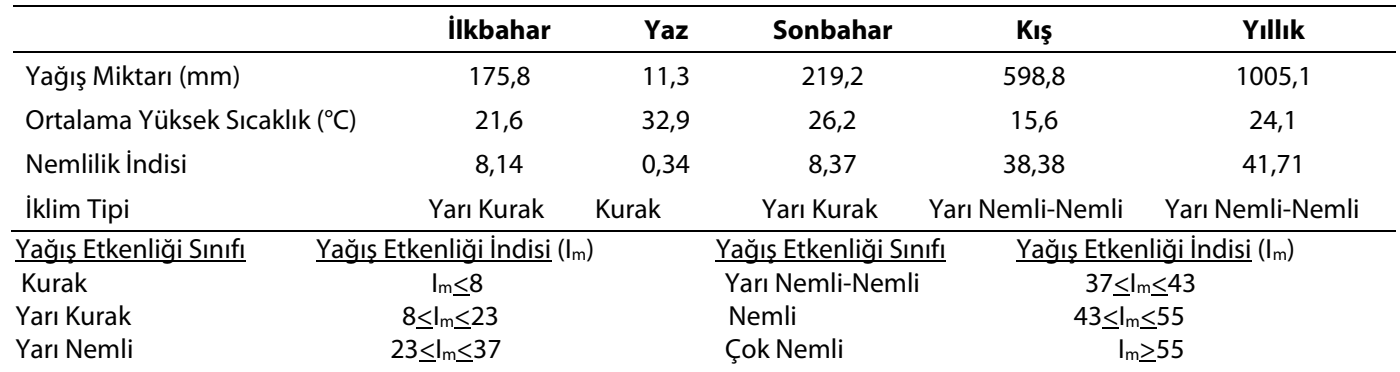

\section{Kurakçıl Peyzaj}

Günümüzde peyzaj mimarlığı çalışmaları mevcut kaynakların sadece insanların lehine tüketilmesine değil, aynı zamanda doğanın lehine korunması gerekliliğine dayanmaktadır. Canlı materyallerin kullanıldığı, dolayısıyla su kullanımının mutlak gerekli olduğu peyzaj alanlarında, su kaynaklarının en akılcı kullanımını sağlayan planlama prensiplerini içeren akım "Xeriscape" olarak nitelendirilmiştir. Xeriscape terimi Yunanca kurak anlamına gelen "Xeros" ve İngilizce'de peyzaj anlamına gelen "Landscape" kelimelerinden türetilmiştir. Bu anlayış 1980'li yılların başında Colarado eyaletinin Denver kentinde ortaya çıkmıştır (Welsh, 2000; Wilson ve Feucht, 2007). Xeriscape'de uygun planlama ve tasarım, toprak hazırlığı ve toprağın iyileştirilmesi, uygun bitki türlerinin seçimi, kuraklığa dayanıklı çim alanların oluşturulması, etkin sulama, malçlama ve uygun bakımdan oluşan bir yaklaşım uygulanmaktadır (Welsh, 2000). En önemli ilkelerinin uygun bitki türü seçimi ve kuraklığa dayanıklı çim alanların oluşturulması olduğu düşünülmektedir. Uygun bitki seçimi alanının çevresel koşullarına en uygun bitkilerin seçilmesini ifade etmektedir. Örneğin, sıcak ve kuru güney ve batı bakılı alanlar için kurakçıl, kuzey ve doğu bakılı alanlarda ise nemi seven bitkileri kullanmak gerekmektedir. Diğer bitkilere kıyasla çimler daha fazla miktarda sulamaya ve bakıma gereksinim duymaktadır. Bu yüzden çim alanların azaltılması ve kuraklığa dayanıklı olanlarının tercih edilmesi önem taşımaktadır.

Kurakçıl bitkiler, bölgeden bölgeye farklılık göstermektedir. Bir bölge için tropik olan bir bitki türü, başka bir bölge için kurakçıl olabilmektedir. Bu tür farklılıklar, planlanan alanların doğala daha yakın görünmesini sağlayarak, kendi kimliğini oluşturma açısından da fayda sağlamaktadır (Taner, 2010).

Kurakçıl peyzaj için bitki seçiminde bitki türleri kadar bireylerin sağlıklı olması da önemlidir. Kök topu içindeki köklerin çok ve iyi gelişmiş olması, saçak köklerin de yoğun bulunmasına dikkat edilmelidir. Bitkinin su gereksiniminin belirlenmesi diğer önemli bir konudur. Benzer su gereksinimine sahip bitkiler gruplandırılarak kullanılmalıdır. Böylece sulama işlemleri daha etkin bir biçimde uygulanabilmektedir (Wade ve ark., 2007). Kurakçıl peyzaj bitkisel tasarımlarında kullanılan bitki türleri yoğun bir bakıma gereksinim duymadığından ve genellikle bölgeye uygun doğal türler kullanıldığından daha sürdürülebilir, renkli ve canlı peyzajlar oluşmasına olanak sağlamaktadır. Tüm bunların yanında kurulum ve bakım maliyetleri de oldukça düşük olmaktadır. 


\section{Akdeniz koşullarında kurakçı peyzaj düzenlemelerinde kullanılabilecek bitki türleri}

Ülkemizde son yıllarda yapılan araştırmalarda iklim değişikliğinin, Ege ve Akdeniz gibi sıcak bölgelerde etkilerinin daha ağır olabileceği vurgulanmaktadır. Sıcaklıkların artmasıyla toprakta meydana gelen buharlaşma ve bitkilerdeki evapotranspirasyonun artmasıyla bitki strese gireceğinden, kuraklığa dayanıklı türlerin geliştirilmesi zorunlu hale gelecektir. İklim analizleri sonucuna göre Antalya'da 5 ay süren kurak dönem, peyzaj çalışmalarında kuraklıkla mücadele konusunda ek çalışmalara gereksinim duyulduğunu göstermektedir. Çetin (2016) yapmış olduğu çalışmada Antalya'nın doğal özelliklerinin dikkate alındığı, kurakçı peyzaj uygulamalarında bitkisel tasarımda kullanılabilecek bitki türlerine yönelik bir bitki listesi oluşturmuştur. Bu listede 200 bitkinin Latince ve Türkçe adı, orijini, tipi, yaprak dökme durumu, peyzaj için çekiciliği (çiçek rengi, çiçek açma zamanı, yaprak rengi ve özelliği, meyve vb.), fidanlıklarda bulunabilirliği ve Akdeniz bölgesinin doğal bitki örtüsündeki varlığına ilişkin bilgiler de bulunmaktadır. Bu listenin ayrıntılı olarak değerlendirilmesi sonucunda bitkilerden yalnız 36 adedinin fidanlıklarda bulunmadığı (Çizelge 3), 42 adedinin ise hem Akdeniz doğal bitki örtüsünde hem de fidanlıklarda bulunduğu (Çizelge 4) tespit edilmiştir. Doğal bitki örtüsünde bulunan 65 adet türden, 23 adedi fidanlıklarda olmayan türlerdir, fidanlıklarda olmayan doğal bitki örtüsünde bulunan bu bitkilerden bazıları; Cistus creticus, Coronilla juncea, Erica arborea, Genista acanthoclada, Globularia alypum ve Tamarix gallica'dır. Türlerin orijini çoğunlukla (\%31.5) Akdeniz bölgesidir. Bitki tipleri açısından değerlendirildiğinde ilk sıralarda çalı, ağaç ve çok yıllık otsu türler yer almaktadır (Şekil 2). Etli yaprak ve gövdesinde su depo etme özelliğindeki sukkulent bitkiler, toplam bitkilerin \%10.5'ini oluşturmaktadır. Bitkilerin yaprak dökme durumlarına bakıldığında 96 adet herdemyeşil, 2 adet herdemyeşilyarı herdemyeşil, 45 adet yaprak döken, 2 adet yaprak döken-yarı herdemyeşil ve 5 adedinin yarı herdemyeşil olduğu saptanmıştır (Şekil 3). Bu türlerin peyzaj için çekicilikleri incelendiğinde çoğunlukla çiçekleri (ağırlıklı olarak sarı ve pembe renkli) ile öne çıktığı görülmektedir.

Çizelge 3. Fidanlıkta bulunmayan bitki türleri

Table 3. Plant species not found in the nursery

\begin{tabular}{llll}
\hline Ajuga reptans & Cistus villosus & Genista acanthoclada & Polygonum aubertii \\
Alcea rosea & Colutea arborescens & Globularia alypum & Quercus coccifera \\
Bouteloua gracilis & Coronilla juncea & Hedera helix & Rhus glabra \\
Buchloe dactyloides & Cotinus coggygria & Hippophae rhamnoides & Rubus sanctus \\
Calycotome villosa & Crithmum maritumum & Jasminum fruticans & Ruscus aculeatus \\
Capparis spinosa & Cytisussp. & Paliurus spina-christi & Salvia triloba \\
Cistus creticus & Daphne gnidioides & Paspalum notatum & Satureja thymbra \\
Cistus parviflorus & Daphne sericea & Phillyrea latifolia & Tamarix gallica \\
Cistus salviifolius & Erica arborea & Phlomis fruticosa & Tanacetum densum \\
\hline
\end{tabular}

Çizelge 4. Hem fidanlıkta hem de doğal bitki örtüsünde bulunan türler Table 4. Species found both in nursery and natural vegetation

\begin{tabular}{llll}
\hline Allium neapolitanum & Iris sp. & Pyracantha coccinea & Salvia officinalis \\
Arbutus andrachne & Juniperus phoenicea & Pinus brutia & Santolina rosmarinifolia \\
Arbutus unedo & Laurus nobilis & Pinus pinea & Sedum sediforme \\
Artemisia arborescens & Lavandula officinalis & Pistacia terebinthus & Senecio maritimus \\
Celtis australis & Lavandula stoechas & Prunus amygdalus & Spartium junceum \\
Ceratonia siliqua & Lavatera sp. & Punica granatum & Styrax officinalis \\
Cercis siliquastrum & Lobularia maritima & Quercus suber & Tamarix tetrandra \\
Crataegus monogyna & Lonicera etrusca & Rhamnus alaternus & Teucrium fruticans \\
Cupressus sempervirens & Myrtus communis & Rhus coriaria & Vitex agnus-castus \\
Cynodon dactylon & Nerium oleander & Rosmarinus officinalis & Vitis vinifera \\
Dianthus sp. & Olea europaea & & \\
\hline
\end{tabular}




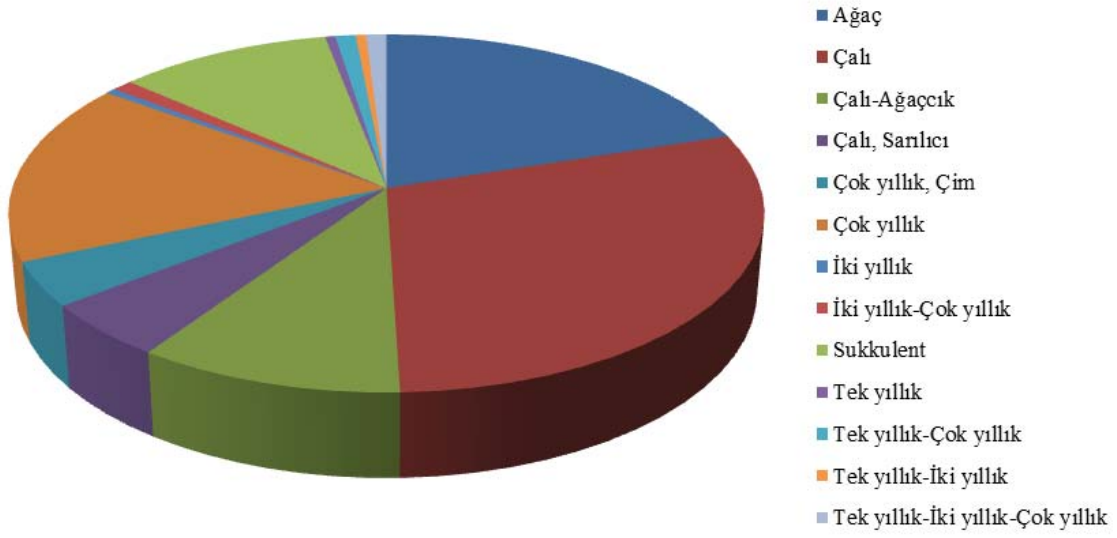

Şekil 2. Bitki tablosundaki bitkilerin tiplerine göre dağılımı (adet)

Figure 2. Distribution of plant species according to types in the plant table (piece)

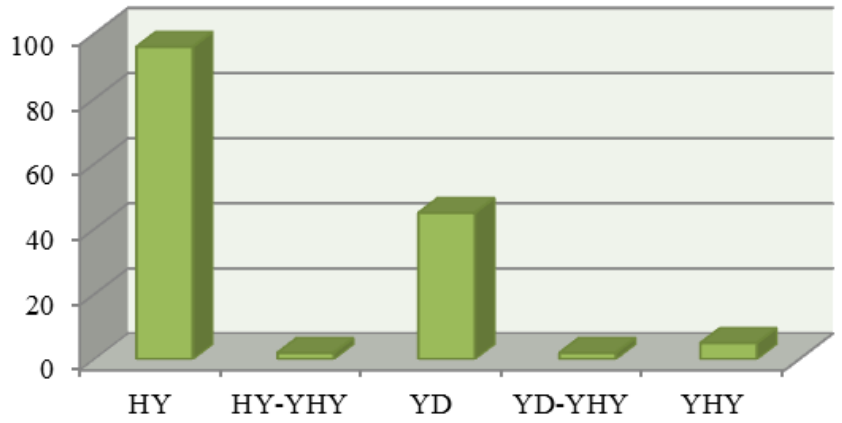

HY: Herdemyeşil YD: Yaprak döken YHY: Yarı herdemyeșil

Şekil 3. Bitki tablosundaki bitkilerin yaprak dökme durumlarına göre dağılımı (adet)

Figure 3. Distribution of plants in the plant table according to their leaf drop status (piece)

\section{SONUÇ}

Dünya nüfusunun artması, şehirleşme, iklim değişiklikleri, orman tahribatları ve çölleşme sonucunda kuraklık; toplum, çevre ve ülkeleri tehdit eder boyutlara ulaşmaktadır. Kuraklık meteorolojik karakterli doğal afetler içerisinde insanlık için en yüksek risk taşıyan bir afettir (Topçuoğlu ve ark. 2004).

Knox (2005), Cleveland (2008) ve Çakıroğlu (2011) gibi pek çok araştıııcı çalışmalarında klasik peyzaj düzenleme yaklaşımından vazgeçilip, su tasarrufu sağlayan peyzaj tasarımlarının yaygınlaşması gerektiğini vurgulamışlardır. Ertop (2009), Mansuroğlu ve Kınıklı (2010), Tülek ve Barış (2011), Baykan ve Birişçi (2013) çalışmalarında kuraklığa karşı doğal bitki türleri kullanımının önemine dikkat çekmiştir. Doğal bitkiler, bölgenin kendi kimliğini, kültürünü yansıtma ve türlerin sürekliliğini sağlama açısından önem taşımaktadır. Ancak fidanlıklarda doğal türleri bulma konusunda sıkıntılar yaşanmaktadır. Fidanlık sahipleri yurtdışından yüksek maliyetlerle bitki getirme yerine, doğal bitki üretimine ağırlık vererek düşük maliyetlerle bu bitkileri üretmeye yönelmesi bu açıdan önem taşımaktadır. Yeşil alan düzenlenmelerinde doğal yapı özelliklerine göre yapılan bitkisel tasarımlar ile estetik ve fonksiyonelliği buluşturan çevreci tasarımlara gereksinim vardır. Bu yaklaşımlardan su kaynaklarının akılc kullanımını sağlayan, aynı zamanda yeşil alanların yapım ve bakım maliyetlerini düşüren, kurakçıl peyzaj uygulamalarıyla, hem doğa dostu hem de ekonomik peyzaj düzenlemeleri mümkün olabilecektir. Çakmak (Tarihsiz), bitki su tüketimini etkileyen faktörleri, bitki su tüketimi hesaplama yöntemlerini açıklamıştır. Bitkileri su gereksinimlerine göre grup halinde kullanımı önemli ölçüde su tasarrufu sağlamaktadır. Peyzaj çalışmalarında bitki seçimlerinde daha fazla özen gerektiren, yabancı yurtlu bitki anlayışından vazgeçilerek, kuraklığa dayanıklı türlerin özellikle de doğal olanlarının kullanımı, mevsimlik kullanımının azaltılması, çim alanların 
mümkün olduğunca azaltılması ya da kuraklığa dayanıklı çim türlerine ve sukkulent tür kullanımına ağırlık verilmesi gereklidir. Egzotik bitkiler diğer türlere göre pahalı olup, beraberinde getirebilecekleri hastalık ve zararlıları lokal türlere de yayarak daha büyük zararlara yol açabilmektedir.

Taner (2010), Çakıroğlu (2011), Şahin (2013), Tülek ve Barış (2011) kuraklığa dayanıklı bazı bitkiler hakkında bilgi vermişlerdir. Keane (1995), Welsh (2000), Wade ve ark. (2007) bitkileri tiplerine göre gruplayarak, yaprak dökme durumu, güneş-gölge istekleri gibi özelliklere yer vererek, Keane (1995) ve Wade ve ark. (2007) ek olarak sulama zonları hakkında da bilgi vererek öneri bitki listelerini hazırlamışlardır. Gerek yurt içinde gerekse yurt dışında yürütülen çalışmalarda alana özgü oluşturulmuş, fidanlıklarda bulunma durumlarının incelendiği, kurakçıl peyzaj

\section{KAYNAKLAR}

Akalın, Ş. 1952. Büyük Bitkiler Kılavuzu. Tarım Bakanlığı Köycülük Şubesi, Ankara, $751 \mathrm{~s}$.

Altan, T. 2005. Doğal Bitki Örtüsü. Çukurova Üniversitesi Ziraat Fakültesi Yayın No:235, Adana, $200 \mathrm{~s}$.

Atıl, A., B. Gülgün ve İ. Yörük. 2005. Sürdürülebilir kentler ve peyzaj mimarlı̆̆ı. Ege Üniversitesi Ziraat Fakültesi Dergisi, $42(2): 215-226$.

Avcıoğlu, R. ve H. Geren. 2012. Bazı sıcak iklim çim buğdaygillerinin Akdeniz iklimindeki performansları üzerine araştırmalar. Anadolu Journal of Aegean Agricultural Research Institute, 22(1):1-17, Mara.

Baktır, İ. 1994. Dendroloji 1 Gymnosperm'ler-Açıktohumlular. Akdeniz Üniversitesi Ziraat Fakültesi Yayın No:4, Antalya, 65 s.

Baykan, N.M. ve Biriş̧̧i, T. 2013. Ege Üniversitesi Ziraat Fakültesi Bahçesi Örneğinde Sürdürülebilir Peyzaj Tasarımı Yaklaşımıla Xeriscape, V. Süs Bitkileri Kong. pp 523-528

Bridwell, F.M. 2003. Landscape Plants Their Identification Culture And Use Second Edition. U.S., p. 610.

Burnie, G., S. Forrester, D. Greig, S. Guest, M. Harmony, S. Hobley, G. Jackson, P. Lavarack, M. Ledgett, R. Mcdonald, S. Macoboy, B. Molyneux, D. Moodie, J. Moore, D. Newman, T. North, K. Pienaar, G. Purdy, J. Silk, S. Ryan ve G. Schien. 2004. Botanica. Italy, p. 1020.

Ceylan, G. 1999. Dış Mekan Süs Bitkileri ve Peyzajda Kullanımları. Flora Yayınları, İstanbul, $216 \mathrm{~s}$.

Cleveland, H. 2008. Water conservation and efficiency. p. 35. Erişim: Şubat, 2014.

Çakıroğlu, G. 2011. Peyzaj tasarımında su tasarrufuna yönelik güncel uygulamaların irdelenmesi İstanbul örneği. İstanbul Üniversitesi, Yüksek Lisans Tezi, İstanbul, 174 s.

Çakmak, B. Tarihsiz. Bitki su tüketimi ve sulama suyu ihtiyacının belirlenmesi. 62 s. http://arsiv.agri.ankara.edu.tr/irrigation/ 1024_sulama_suyu_ihtiyaci.ppt. Erişim: Mart, 2014.

Çepel, N. 1995. Orman Ekolojisi. İstanbul Üniversitesi. Orman Fakültesi Toprak İlmi ve Ekoloji Anabilim Dalı, Dördüncü Baskı, İstanbul, $536 \mathrm{~s}$.

Çetin, N. 2016. Akdeniz koşullarında kurakçıl peyzaj uygulanabilirliğinin irdelenmesi. Akdeniz Üniversitesi, Yüksek Lisans Tezi, Antalya, $134 \mathrm{~s}$. çalışmalarında kullanılabilecek bitkileri ve özelliklerini içeren bir çalışma bulunamamıştır. Sonuç olarak ayrıntılı bir literatür taraması ve fidanlıklar temelindeki araştırmaya dayanarak Çetin (2016) tarafından hazırlanan liste, peyzaj alanlarında kuraklığa dayanıklı tür kullanımının yaygınlaştııılması ve Akdeniz kıyı alanları başta olmak üzere benzer ekolojideki bölgelerimizde kullanımı için katkı sağlaması açısından önem taşımaktadır. Doğru bitki seçimi için öncelikle doğal yapı özelliklerinin analiz edilmesi, sonrasında estetik ve fonksiyonel açıdan uygun türlerin seçimi sürdürülebilirlik açısından mutlak fayda sağlayacaktır. Ayrıca fidanlıklarda bulunmayan, kuraklığa dayanıklı türlerin üretimi için fidanlıklar, ilgili kurum ve kuruluşların dikkatinin çekilmesi ile peyzajda çeşitlilik ve çekicilik yaratılmasına olanak sağlanabilecektir.

Ebcioğlu, N. 2004. Bahçe Çiçekleri. Remzi Kitabevi, İstanbul, 175 s.

Erinç, S. 1965. Yağış Müessiriyeti Üzerine Bir Deneme ve Yeni Bir İndis. İ.Ü. Coğrafya Enstitüsü Yayınları No:41, İstanbul.

Ertop, G. 2009. Küresel 1sınma ve kurakçl peyzaj planlaması. Yüksek Lisans Tezi, Ankara Üniversitesi, Ankara, 164 s.

Ferguson, N. 1986. Right Plant Right Place. Pan Books, London, p. 292.

Filippi, O. 2008. The Dry Gardening Handbook. Thames and Hundson Ltd., France, p. 208.

Gildemeister, H. 2002. Mediterranean Gardening A Waterwise Approach. University of California Press, p. 208.

Göktürk, R.S. 1994. Antalya şehir florası üzerinde bir araştırma. Yüksek Lisans Tezi, Akdeniz Üniversitesi, Antalya, 226 s.

Gül, A., H. Özçelik ve Ö.F. Uzun. 2012. Isparta Yöresindeki Bazı Doğal Yerörtücü Bitkilerin Adaptasyonu ve Özellikleri, Süleyman Demirel Üniversitesi Fen Bilimleri Enstitüsü Dergisi, 16(2):133-145.

Horowitz, M. 1996. Bermudagrass (Cynodon dactylon): A History of the Weed and Its Control in Israel, Phytoparasitica. 24(4):305 320.

Karahan, F. ve İ. Angın. 2008. Yeşil alan uygulamalarında su tüketiminin asgariye indirilmesi için sukkulent bitki türlerinden yararlanma. TMMOB 2. Su Politikaları Kongresi, Ankara, s. 291-296.

Kaya, B. ve C. Aladağ. 2009. Maki ve Garig Topluluklarının Türkiye'deki Yayılış Alanları ve Ekolojik Özelliklerinin İncelenmesi. Selçuk Üniversitesi Sosyal Bilimler Enstitüsü Dergisi, 22:67-80.

Keane, T. 1995. Water wise landscaping guide for water management planning. Utah State University Extension, p. 96.

KHGM (Köy Hizmetleri Genel Müdürlüğü), 1993a. Toprak Haritası.

KHGM (Köy Hizmetleri Genel Müdürlüğü), 1993b. Antalya İli Arazi Varlı̆̆ı. Köy Hizmetleri Genel Müdürlüğü, Etüt ve Proje Dairesi Başkanlı̆̆ı, Ankara, 109 s.

Knox, G.W. 2005. Landscape design for water conservation. University of Florida IFAS Extension, p. 3. 
Konyaaltı Belediyesi, 2014. İlçenin son sınırlarını gösteren harita, Emlak ve İstimlak Müdürlüğü.

Konyaaltı Kaymakamlığı, 2015. http://www.konyaalti.gov.tr/. Erişim: Eylül, 2015.

Kumar, A. and A. Singh. 2012. Review on Hibiscus rosa sinensis. International Journal of Research in Pharmaceutical and Biomedical Sciences, 3(2):534-538.

Mamıkoğlu, N.G. 2012. Türkiye'nin Ağaçları ve Çalıları. İstanbul, NTV Yayınları, $727 \mathrm{~s}$

Mansuroğlu, S. ve P. Kınıklı. 2010. Antalya Kent Merkezindeki Yerel Bitki Türleri ve Bunların Peyzaj Mimarlığı Calıșmalarında Kullanım Alanları. IV. Süs Bitkileri Kongresi Bildiriler Kitabı. Mersin, s. 272-281.

MGM (Meteoroloji Genel Müdürlüğü), 2015. Antalya İli (Antalya Meteoroloji 4. Bölge Müdürlüğü ve Antalya Havaalanı iklim istasyonu) iklim verileri. Antalya.

MTA (Maden Tetkik ve Arama Genel Müdürlüğü), 1997. 1|100.000 Ölçekli L11 paftası Jeoloji Haritası.

Odabaş, A. 1989. Park ve Bahçe Süs Bitkileri. Kocaoluk Yayınevi, Yalova, $184 \mathrm{~s}$.

Oral, N. 1999. İç Mekan Süs Bitkileri. Ezgi Kitabevi, Bursa, 374 s.

Orçun, E. 1972. Özel Bahçe Mimarisi Dendroloji Cilt I İğne Yapraklı Ağaç ve Ağaçcıklar Ders Kitabı. Ege Üniversitesi Ziraat Fakültesi Yayın No:196, İzmir, 383 s.

Orçun, E. 1975. Peyzaj Mimarisi Dendroloji Cilt II Yapraklı Ağaç ve Ağaçcıkların Özellikleri ve Peyzaj Mimarisinde Kullanılışları. Ege Üniversitesi Ziraat Fakültesi Yayın No:266, İzmir, $291 \mathrm{~s}$.

Önder, S. ve A.T. Polat. 2009. Yeşil alan uygulamalarında su tasarrufuna yönelik olarak sukkulent yer örtücü bitki türlerinden yararlanma. 1.Ulusal Kuraklık ve Çölleşme Sempozyumu Bildiriler Kitabı. Konya, s. 480-485.

Randhawa, G.S. ve A. Mukhopadhyay. 2004. Floriculture in India. Mumbai, p. 660.

Redbud Chapter Western Nevada and Placer counties 2008. Xeriscaping with Drought Tolerant California Native Plants. p. 2.

Schellman, A. 2009. Water-Wise Gardening. University of California Cooperative Extension, Stanislaus County, p. 31.
Stephens, J.M. 2015. Purslane-Portulaca oleracea L. University of Florida, IFAS Extension, p. 1. https://edis.ifas.ufl.edu/pdffiles/ MV/MV11800.pdf. Erişim: Kasım, 2015.

Şahin, N. 2013. Kurakçıl peyzaj düzenlemesinde suyun etkin ve akılcı kullanımı xeriscape. Yüksek Lisans Tezi, Muğla Sttkı Koçman Üniversitesi, Muğla, $65 \mathrm{~s}$.

Taner, T.M. 2010. Peyzaj düzenlemesinde suyun etkin kullanımı kurakçl peyzaj. Yüksek Lisans Tezi, Ege Üniversitesi, İzmir, 56 s.

Topçuoğlu, K., M. Özgürel ve G. Pamuk. 2004. Türkiye için yeni bir kuraklık indisi denemesi. Ege Üniversitesi Ziraat Fakültesi Dergisi, 41(3):145-153

TÜİK (Türkiye İstatistik Kurumu), 2015. Adrese dayalı nüfus kayıt sistemine göre, il nüfusları, büyükşehir belediye nüfusları, mahalle nüfusları istatistikleri. http://www.tuik.gov.tr/. Erişim: Mart, 2015.

Tülek, B. ve E. Barış. 2011. Orta Anadolu iklim koşullarında su etkin peyzaj düzenlemelerinin değerlendirilmesi. Mustafa Kemal Üniversitesi Ziraat Fakültesi Dergisi, 16(2):1-13.

Ulubelen, A., B. Terem ve Tuzlac1, E. 1986. Coumarins and flavonoids from Daphne gnidioides. Journal of Natural Products, 49(4):692 694

University of California Cooperative Extension California Department of Water Resources, 2000. A Guide to Estimating Irrigation Water Needs of Native Plantings in California. p. 150.

Wade, G.L., J.T. Midcap, K.D. Coder, G. Landry , A.W. Tyson and N.W. JR. 2007. Xeriscape A Guide to developing a water-wise landscape. The University of Georgia College of Agricultural and Environmental Sciences, p. 40.

Walter, H., 1970. Vegetationszonen und Klima. E. Ulmer, Stuttgart, Germany.

Welsh, D.F. 2000. Xeriscape North Carolina. National Zeriscape Council, USA, p. 28

Wilson, C. and JR. Feucht. 2007. Xeriscaping: creative landscaping. Colorado State University Extension, Colorado, p. 3.

Yaltırık, F. 1984. Türkiye Meşeleri Teşhis Kılavuzu. Tarım Orman ve Köyişleri Bakanlığı Genel Müdürlüğ̈̈ Yayını, İstanbul, 64 s.

Yılmaz, K.T. 1996. Akdeniz Doğal Bitki Örtüsü. Çukurova Üniversitesi Genel Yayın No: 141, Yardımcı Ders Kitapları, Yayın No:13, Adana, $179 \mathrm{~s}$. 